\title{
Resident Performed Sutureless Manual Small Incision Cataract Surgery (MSICS): Outcomes
}

\author{
Praveen Subudhi' \\ Sweta Patro' \\ B Nageswar Rao Subudhi ${ }^{1,2}$ \\ Silla Sitaram' \\ Zahiruddin Khan ${ }^{2}$ \\ Chandan Mekap' \\ 'Cataract Department, Ruby Eye \\ Hospital, Berhampur, Ganjam, Odisha, \\ India; ${ }^{2}$ Ophthalmology Department, \\ Hitech Medical College, Bhubaneswar, \\ India
}

Purpose: To show the surgical and visual outcomes of a resident-performed manual small incision cataract surgery.

Study Type: Retrospective observational case series.

Study Setting: Ruby Eye Hospital.

Materials and Methods: Manual small incision cataract surgery was performed on 339 uncomplicated cataract cases by three in-house residents. Preoperative visual acuity and vision with a pinhole were meticulously noted in the record sheets. All patients underwent thorough preoperative evaluation with the help of a slit lamp. Eyes with corneal guttae, undilated pupils, pseudo-exfoliation, raised intraocular pressure and posterior segment abnormalities were excluded from the study. The mean patient age was 59 years (min: 47 years and max: 85 years). Forty-seven percent were males, and the rest were females. The mean uncorrected preoperative visual acuity recorded was $1.3 \operatorname{logMAR}$ units (max: 1 and min: 1.6, Std dev: 0.4). Forty-two percent of the eyes had dense nuclear cataracts ( $\geq$ Nuclear Sclerosis grade III from LOCS II).

Results: The mean postoperative visual acuity recorded was $0.4 \log$ MAR units [standard deviation $0.3 \log$ MAR units (max: 1 and min: 0.1 p-value $<0.001$ )]. Forty-three cases $(12.6 \%)$ had tunnel-related complications (premature entry/button hole). Thirty-six cases $(10.6 \%)$ had iatrogenic prolapse of the iris tissue. Eight cases $(2.3 \%)$ had a runaway capsulorhexis, while 18 cases $(5.3 \%)$ had iatrogenic posterior capsular rupture. Two cases $(0.58 \%)$ had a large zonular dialysis. Ten cases $(2.9 \%)$ were retaken to the operating room again for repeat intervention.

Conclusion: The ophthalmic resident learning curve for manual small incision cataract surgery is steep, unlike what is reported in the literature. A good training program with a special emphasis on wound construction is of paramount importance for future residents.

Keywords: MSICS, resident training, wound construction

\section{Introduction}

Ophthalmology residency training in states is variable throughout the country. ${ }^{1}$ However, training young residents is a critical part in the transformation from supposition to an interactive heuristic approach of learning. ${ }^{2}$ Hence, designing a resident training program is helpful for bringing uniformity to teaching across the globe, but it requires a basic understanding of the stumbling blocks of all residents. ${ }^{3}$ Cataracts still remain the most common cause of ocular morbidity in the majority of developing countries. ${ }^{4}$ Ophthalmic residents mostly have their first-hand surgical experience with cataract surgery. ${ }^{5}$ Manual small incision cataract surgery is the most commonly performed cataract surgery across all
Correspondence: Praveen Subudh Ruby Eye Hospital, Govinda Vihar, Sushruta Nagar, Berhampur, Ganjam, Odisha, 76000I, India

Email subudhipraveen@gmail.com 
training institutes in India. ${ }^{6}$ Retrospective analysis of the literature shows many published data regarding the resident learning curve for phacoemulsification, but there are only three published studies about MSICS. ${ }^{6-8}$ Hence, we need a larger database from various centers to develop a universal resident training program. To the best of our knowledge, the only article depicting the resident training curve and adverse events related to surgery was from a tertiary care centre in southern India. We therefore retrospectively analysed the visual outcome and adverse events related to MSICS performed by our residents.

\section{Materials and Methods}

This retrospective clinical study included the medical records of 339 uncomplicated cataract cases who underwent manual small incision cataract surgery with intraocular lens implantation by three residents at Ruby Eye Hospital in Berhampur, Odisha, India. All patients had provided informed written consent in congruence with the tenets of the Declaration of Helsinki. The study was taken approval from the institutional ethics committee with a reference number of REH03.

\section{Preoperative Examination}

Demographic data of all patients were collected and are listed in Table 1. All patients had comprehensive ophthalmologic examinations, including uncorrected distance visual acuity, visual acuity with a pin hole, diffuse torch light examination of both eyes, pupil reaction, slit-lamp evaluation, Goldmann applanation tonometry, pupil dilation with tropicamide and phenylephrine, dilated pupil measurement, and posterior segment evaluation with a slit-lamp biomicroscopy using a 90D fundoscopic lens. Grades of cataract were well documented in preoperative worksheet (Figure 3A).

Table I Demographics and Biometry of Study Patients

\begin{tabular}{|l|l|}
\hline \multicolumn{2}{|l|}{ Demographics } \\
\hline Mean age (in years) & $59.3( \pm 3.2)$ \\
\hline Laterality & Right (52.8\%), Left (47.19\%) \\
\hline Sex & Male (53\%), Female (47\%) \\
\hline Mean IOL power (in diopters) & $19.7 \pm 1.4$ \\
\hline Anaesthesia* & Peribulbar \\
\hline
\end{tabular}

Note: *All 339 patients underwent cataract surgery under peribulbar anaesthesia.
Patients with corneal guttae, central corneal opacity, relative afferent pupillary defects, pseudo-exfoliation syndrome, small pupils, advanced glaucoma, phacodonesis and vitreomacular disorders were excluded from the study.

\section{Surgical Technique (Figure IA-F)}

Pupillary dilatation was performed by instilling topical tropicamide-phenylephrine $10 \%$ for every 10 minutes for 1 hour prior to the procedure. One drop of ketorolac eye drops were applied 1 hour prior to the implantation. Under strict asepsis, a superior rectus bridle suture was placed. Conjunctival peritomy was from the 10 o'clock to the 2 o'clock position. A straight or preferably smile partial thickness scleral incision sized $5.5 \mathrm{~mm}$ to $7 \mathrm{~mm}$, depending upon the grade of nucleus, was applied with the help of a 15 bard parker blade. A crescent was used to construct a tunnel followed by intracameral entry with the help of a bevel up keratome in order to create three planar selfsealing incisions. Ophthalmic viscosurgical devices (OVD) (hydroxypropyl methyl cellulose) were injected into the intracameral space to create space between the cornea and the lens surface. A side port is made 2 clock hours away from the tunnel, depending on the dominant hand of surgeon (right side, side port for a right-handed surgeon). A $26 \mathrm{G}$ bent cystitome was used to make a continuous curvilinear capsulorhexis of $6.5 \mathrm{~mm}$ to $7.5 \mathrm{~mm}$ in diameter. Cortical cleaving hydrodissection was performed with a balanced salt solution followed by the free rotation of the nucleus and lifting of the nucleus into the intracameral space. Again, OVDs were injected behind the nucleus to push the posterior capsule, next an irrigating vectis attached to a $5 \mathrm{~mL}$ syringe filled with BSSwas guided behind the nucleus in the intracameral space, BSS was injected by pushing the plunger, and the nucleus was removed by pressing the posterior lip of sclero-corneal tunnel. A Simcoe cannula was used to remove the residual cortex using the sclerocorneal tunnel and side port for the sub-incisional cortex. Finally, the posterior chamber intraocular lens was implanted inside the capsular bag under the OVDs. At the end, all OVDs were removed and wound closure was performed by hydrating the side port.

\section{Documentation}

All patient data were meticulously documented, and the intraoperative events were entered in an Excel sheet. Postoperative visual acuity was recorded at day 1 


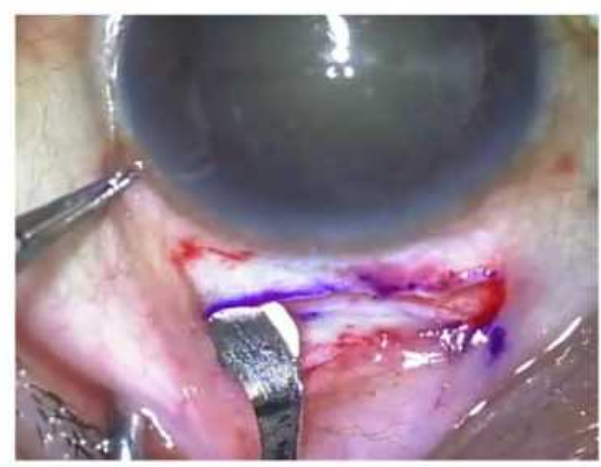

A

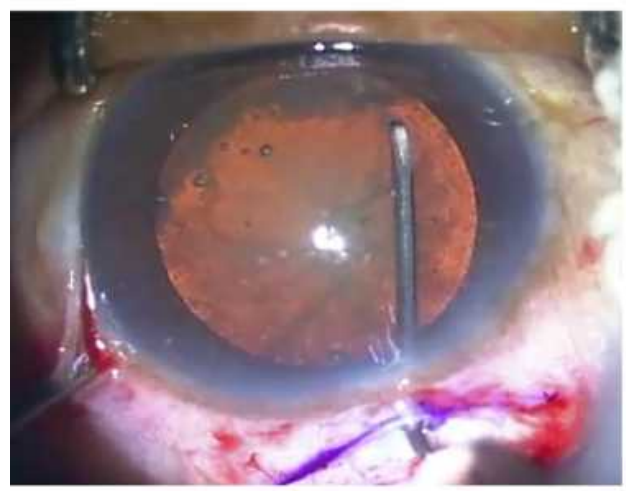

B

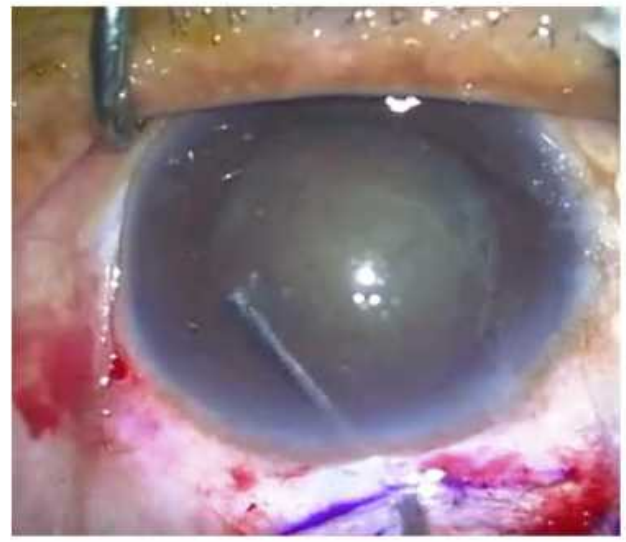

C

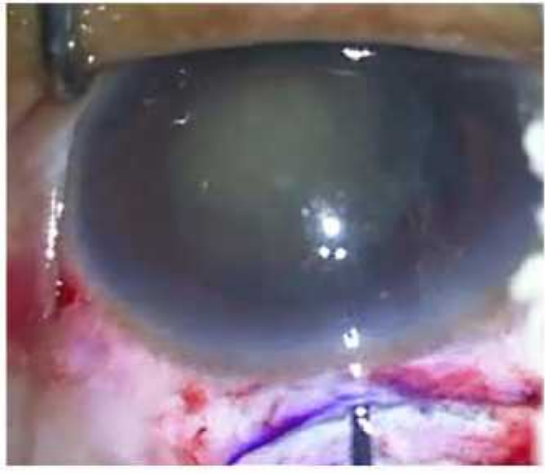

D

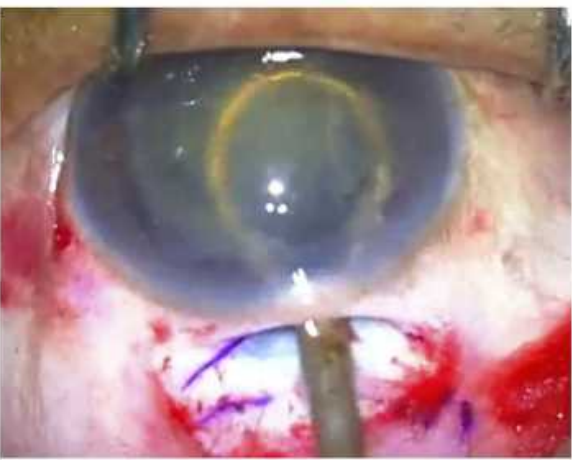

E

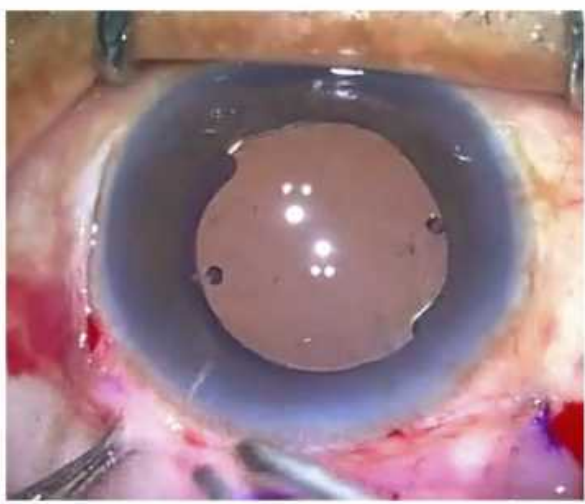

$\mathbf{F}$

Figure I (A) Construction of tunnel in superior quadrant. (B) Demonstrating Capsulorhexis by 26G bent cystitome. (C) Hydrodissection with balance salt solution under the anterior capsular rim. (D) Prolapse of nucleus into anterior chamber by sinskey hook. (E) Introduction of irrigating vector under the prolapsed nucleus in the anterior chamber. (F) Implantation of intraocular lens in capsular bag.

and day 30 of the post-op visits. Auto-refractometer was performed in all cases on day 30 , and the required spectacle correction was dispensed.

\section{Primary Outcome Measures}

Uncorrected visual acuity and best corrected visual acuity.

\section{Results}

\section{Preoperative Visual Acuity (Figure 4A)}

Preoperative mean uncorrected visual acuity recorded was $1.3 \log$ MAR units (Max: 1 and min: 1.6, Std dev: 0.4) corresponding to $6 / 120$ in the Snellen visual acuity chart (SVC). 


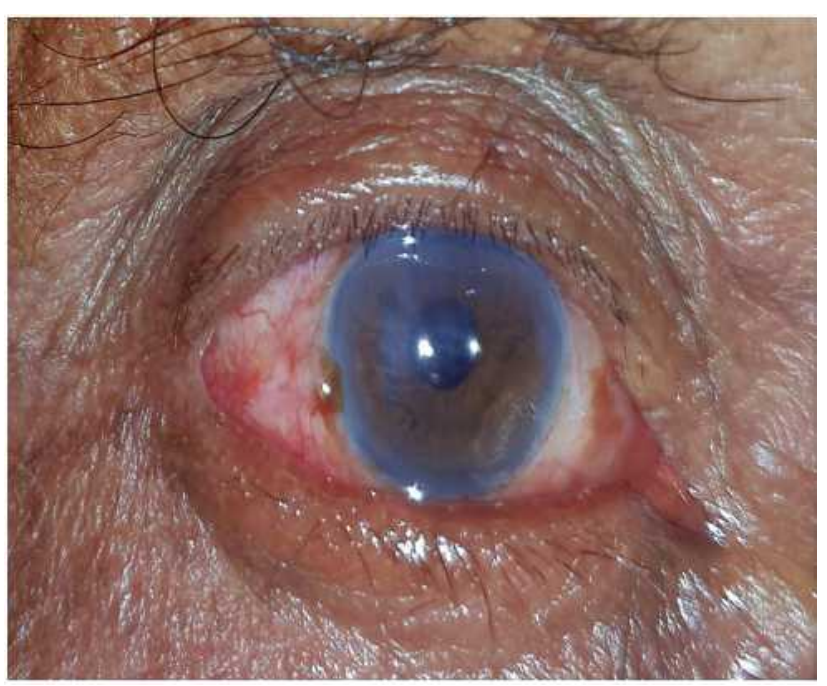

Figure 2 Showing focal corneal edema along paracentral central area PODI.

\section{Intraoperative Complications (Figures 3B and $2 \mathrm{~B}$ )}

\section{Premature Entry}

Premature Entry was encountered in 15 cases (4.4\%). In 13 cases $(3.8 \%)$, a new plane was created from the other end of the incision and a routine tri-planar surgical wound was created, thus salvaging the eye from further adverse events. However, two cases $(0.58 \%)$ had a large premature entry which could not be salvaged, and surgery was completed by a senior surgeon, and three sutures were placed in the surgical wound at the end of surgery.

\section{Button Hole}

Twenty-eight cases $(8.2 \%)$ had a button hole of the tunnel, which means that the scleral flap was very thin, and excessive force was used to create a corneal lip with the help of a blunt crescent, which led to an abnormal external opening of the tunnel. However, in all the patients, a deeper tunnel was constructed from a new point, thus maintaining the tri-planar incision.

\section{Capsulorhexis Radialization}

Eight cases (2.3\%) had a runaway capsulorhexis leading to radialization of the anterior lens capsule. Seven cases $(2.06 \%)$ were managed by slow cortical cleaving hydrodissection by carefully prolapsing the nucleus into the anterior chamber. However, one case $(0.03 \%)$ had a posterior extension of the capsulorhexis with no disturbance of the anterior vitreous face.

\section{Iris Prolapse}

Thirty-six cases $(10.6 \%)$ had iatrogenic prolapse of the iris during intracameral manipulation. Out of 36 cases, 22 cases $(6.4 \%)$ were noted after the delivery of the nucleus, 10 cases $(2.9 \%)$ after hydrodissection and four cases $(1.1 \%)$ before entering into the eye.

\section{Posterior Capsular Rupture}

Eighteen cases $(5.3 \%)$ had inadvertent iatrogenic posterior capsular rupture. Out of 18 cases, 11 cases $(3.5 \%)$ were noted while removing the cortex with the help of a Simcoe cannula, 6 cases $(1.7 \%)$ while implantation of the intraocular lens and 1 case $(0.3 \%)$ after delivery of the nucleus. However, none of these cases ended in aphakia.

\section{Zonular Dialysis}

Two cases $(0.58 \%)$ had a large zonular dialysis, one was 2 clock hours and other was 3 clock hours. These which were managed by anterior vitrectomy and putting a capsular tension ring inside the capsular bag.

\section{Intraoperative Wound Leakage}

Seventeen cases (5\%) had significant wound leakage at the end of the procedure, which was managed by applying $10-$ 0 nylon sutures.

\section{Early Postoperative Complications (Table 2) Transient Corneal Edema (Figure 2)}

Nineteen cases (5.6\%) had postoperative corneal edema on POD1. Out of 19 cases, 12 cases (3.5\%) had complete resolution of corneal edema by the end of 1 week, and seven cases $(2 \%)$ took 2 weeks to recover.

\section{Shallow Anterior Chamber}

Eleven cases (3.2\%) had a shallow anterior chamber on POD1. All cases were given a tight pad and bandage and were evaluated after 24 hours. Nine cases (2.6\%) showed deepening of the anterior chamber and were discharged. However, two cases $(0.58 \%)$ were taken to the OR for wound exploration and suturing of the sclero-corneal tunnel (Table 3).

\section{Updrawn Pupil}

Four cases $(1.17 \%)$ had an updrawn pupil on POD 1, of which two cases $(0.58 \%)$ had mild entanglement of the superior part of the iris to the tunnel. However, the anterior chamber was well maintained and there was minimal reaction, so no further intervention was performed. Two cases $(0.58 \%)$ had large iris prolapse and hence were taken to the OR for repositioning of the iris and suturing of the tunnel (Table 3). 
Number of cases in \%age

Types of Cataract

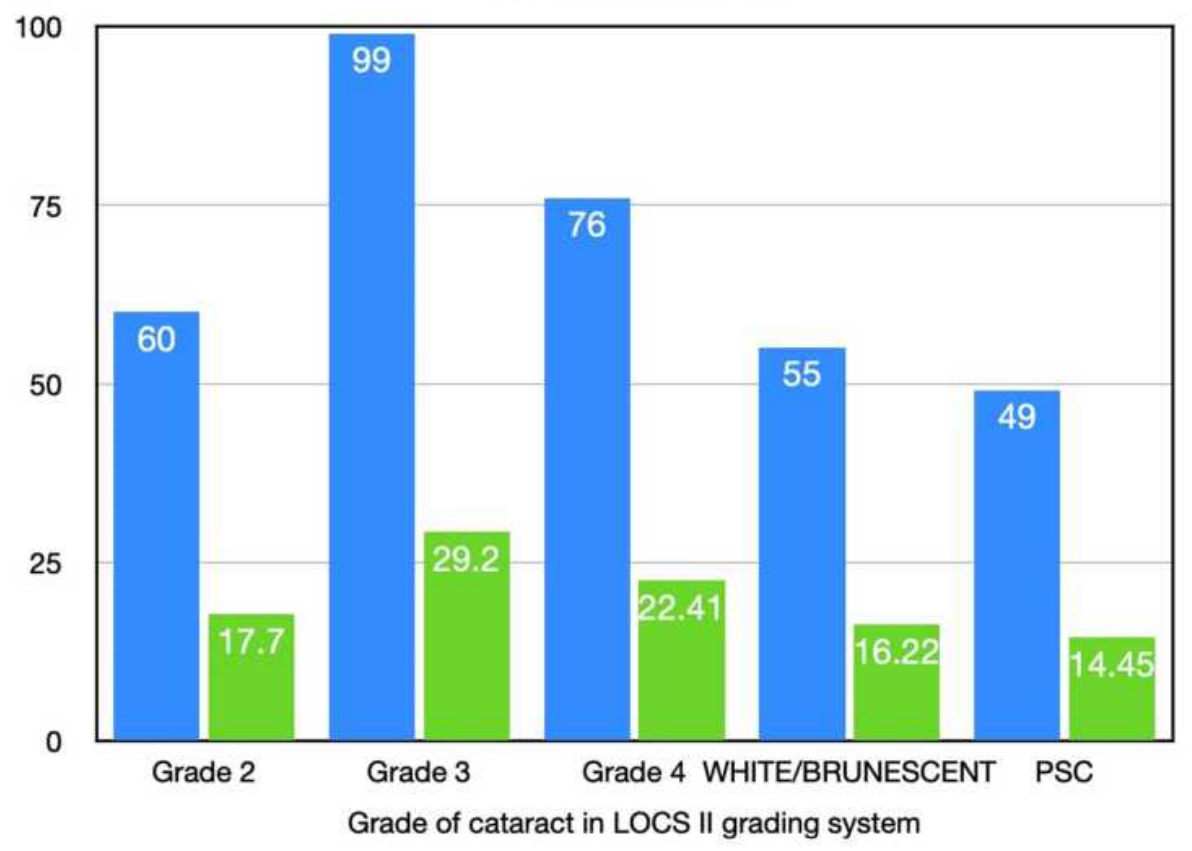

A

Number of cases

Percentage

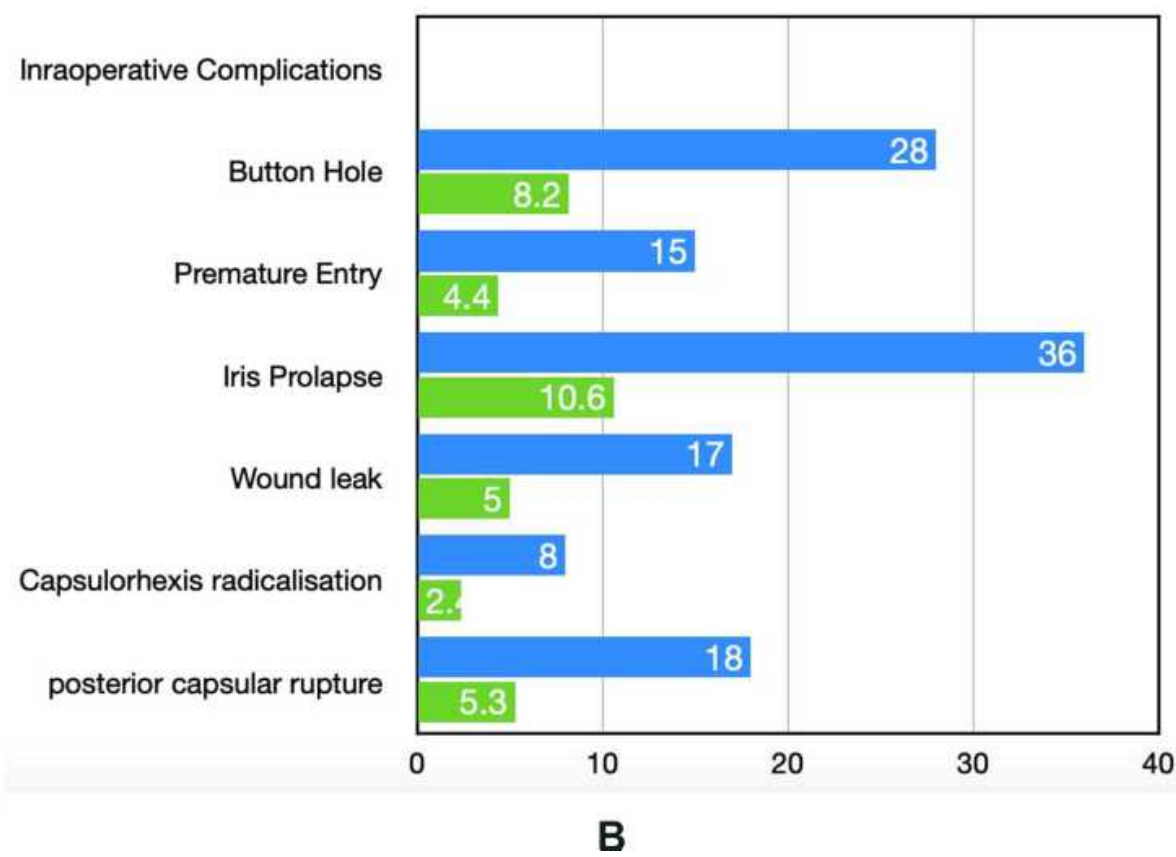

Figure 3 (A) Bar chart showing different grades of nuclear cataract operated. (B) Bar chart demonstrating various adverse events during interoperated period experienced by resident surgeon. 


\section{- pre-op UCVA}

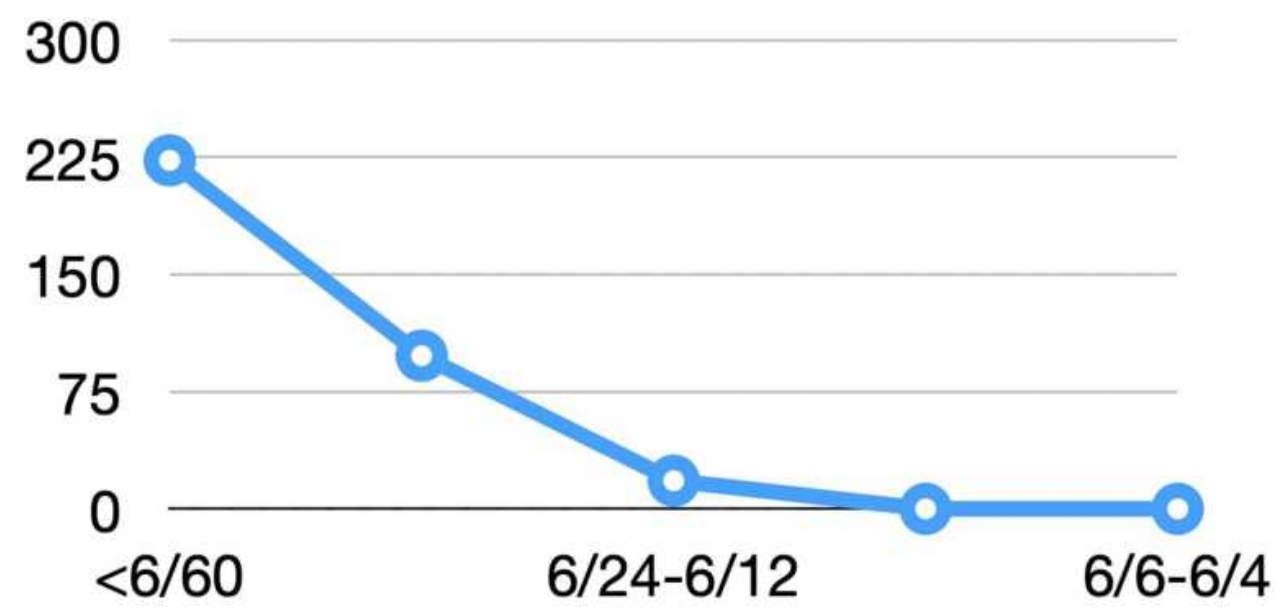

A

Post Operative UCVA Post Operative BCVA

300

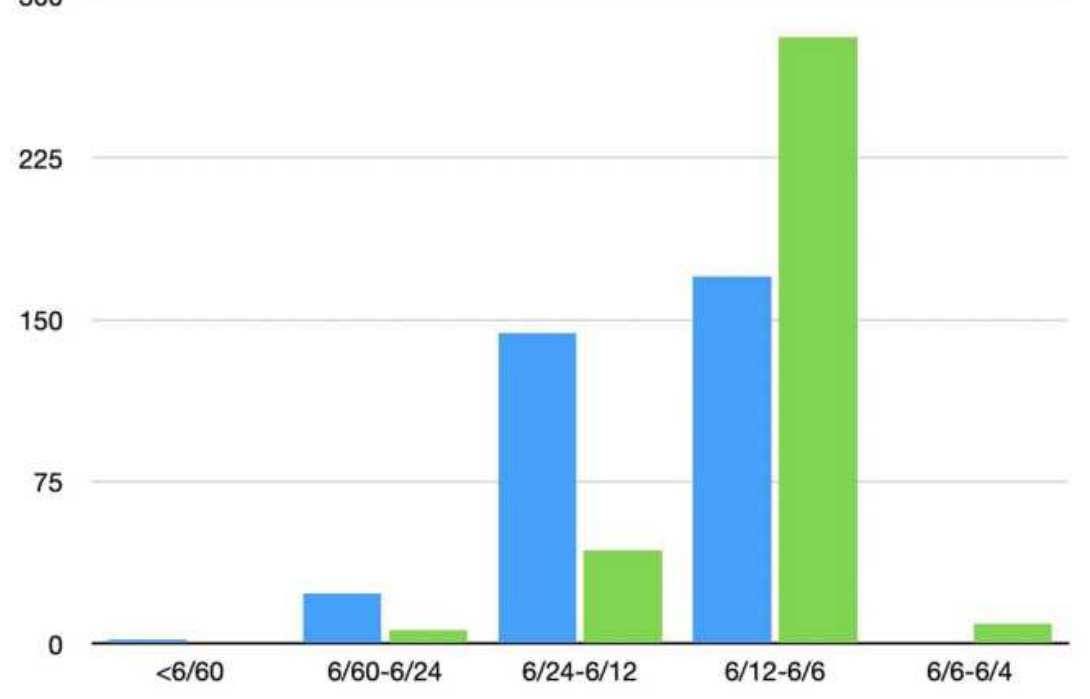

B

Figure 4 (A) Line graph illustrating preoperative visual acuity of all 339 study patients. (B) Comparative Line chart exhibiting postoperative uncorrected visual acuity (UCVA) in logmar units and postoperative best corrected visual acuity in logmar units recorded in all 339 study patients.

\section{Residual Cortex}

Four cases (1.17\%) had residual cortex on POD1. All of the patients were taken to the OR for removal of the cortex (Table 3).

\section{Hyphaema}

Three cases $(0.9 \%)$ had hyphaema or blood in the anterior chamber. Two cases $(0.6 \%)$ had micro-hyphaema, which did not require any further intervention. However, one 
Table 2 Postoperative (PODI) Adverse Events Recorded

\begin{tabular}{|l|c|c|}
\hline Postoperative Complications $^{\$}$ & Number & Percentage* \\
\hline Transient Corneal Edema & 19 & $5.6 \%$ \\
\hline Shallow anterior chamber & 11 & $3.2 \%$ \\
\hline Updrawn Pupil & 4 & $1.17 \%$ \\
\hline Residual Cortex: & 4 & $1.17 \%$ \\
\hline Residual Vitreous: & 2 & $0.58 \%$ \\
\hline Hyphaema & 3 & $1.17 \%$ \\
\hline
\end{tabular}

Notes: *Percentage calculated: number of cases/total number of cases $\times 100$. ${ }^{\$}$ Postoperative adverse events meticulously recorded.

Table 3 List of Cases Taken Up for Resurgery

\begin{tabular}{|l|c|c|}
\hline Resurgery & Number of Cases & Percentage* \\
\hline Resuturing of surgical wound & 2 & $0.58 \%$ \\
\hline Iris release from tunnel & 2 & $0.58 \%$ \\
\hline Cortical cleaning & 4 & $1.17 \%$ \\
\hline Anterior vitrectomy & 2 & $0.58 \%$ \\
\hline
\end{tabular}

Notes: *Percentage calculated: number of cases/total number of cases *100. ${ }^{\$}$ List of cases underwent resurgery on PODI after slit-lamp evaluation.

case $(0.29 \%)$ needed to be posted for the OR to flush out clotted blood from the anterior chamber with the help of a balanced salt solution.

\section{Residual Vitreous}

Two cases $(0.58 \%)$ had a small vitreous strand extending to the section and hence were taken to the OR for anterior vitrectomy.

\section{Postoperative Visual Acuity (Figure 4B, Table 4)}

The mean postoperative uncorrected visual acuity (UCVA) recorded was 0.4 logMAR units (Snellen Equivalent 20/ 50) with a standard deviation of $0.3 \log$ MAR units (Max: 1 and Min: $0.1 \mathrm{p}$-value $<0.001)$. The mean best corrected visual acuity (BCVA) was 0.2 logMAR units (Snellen Equivalent 20/32) with a standard deviation of 0.1 (Max: 0.42 and Min: 0 -value $<0.0001$ ).

\section{Postoperative Spherical Equivalent}

The mean spherical equivalent was -1.2 Diopters (D) with a standard deviation of -0.7 (Max: $-3 \mathrm{D}$ and Min: 0 ). The mean surgical induced astigmatism was $-1.74 \mathrm{D}$ with a standard deviation of $-1.2 \mathrm{D}$ (Max: $-4 \mathrm{D}$ and Min: $-0.25 \mathrm{D})$.

\section{Discussion}

MSICS is a wonderful cataract surgical technique providing excellent postoperative visual rehabilitation without any use of expensive instrumentation. ${ }^{9}$ Hence, it is an extremely useful technique in developing countries and for people with a low socio-economic status. ${ }^{10}$ It is the most commonly performed surgical technique among residents in India. ${ }^{11}$ However, there is a significant learning curve to provide predictable postoperative vision. ${ }^{12}$ Residents need to hone their skills by watching videos and assisting their mentors. ${ }^{13}$

Residents in their initial few cases face significant problems in constructing sclero-corneal tunnels, which is the most critical step of cataract surgery. ${ }^{14,15}$ A wellconstructed tri-planar tunnel reduces anterior chamber

Table 4 Table Showing Preoperative, Postoperative Uncorrected (UCVA) and Postoperative Best Corrected (BCVA) Visual Acuity Interpretation in Logmar Units, Snellen Visual Acuity Chart (20 Feet) and Snellen Visual Acuity Chart (6 Meters)

\begin{tabular}{|l|l|l|l|l|}
\hline Visual Acuity & $\begin{array}{l}\text { Mean Preoperative } \\
\text { Visual Acuity }\end{array}$ & $\begin{array}{l}\text { Mean Postoperative Uncorrected } \\
\text { Visual Acuity (UCVA) }\end{array}$ & $\begin{array}{l}\text { Mean Postoperative Best Corrected } \\
\text { Visual Acuity (BCVA) }\end{array}$ & p-value ${ }^{\#}$ \\
\hline Logmar units & $1.3 \pm 0.4$ & $0.4 \pm 0.3$ & $0.2 \pm 0.1$ & NA* \\
\hline $\begin{array}{l}\text { Snellen Chart } \\
(20 \text { feet) }\end{array}$ & $20 / 400$ & $20 / 50$ & $20 / 32$ & $<0.001$ \\
\hline $\begin{array}{l}\text { Snellen Chart } \\
(6 \text { meters })\end{array}$ & $6 / 120$ & $6 / 15$ & $6 / 9.5$ & $<0.0001$ \\
\hline
\end{tabular}

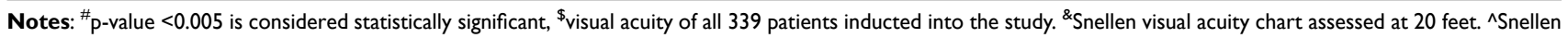
visual acuity chart at 6 meters.

Abbreviation: NA, not applicable. 
instability eventually causing less intraocular trauma. ${ }^{16}$ In our study, we observed that with a blunt crescent, the risk of button holing of the tunnel was high and with a sharp crescent, there were instances of premature entry. Hence, every resident needs to assess the sharpness of the crescent before constructing the tunnel.. ${ }^{17}$

Capsulorrhexis is considered the most crucial step of cataract surgery. ${ }^{18}$ An adequately sized capsulorhexis helps in smooth hydrodissection and prolapse of the nucleus. ${ }^{19}$ Hence, all residents need to practice performing capsulorhexis in wet-labs in a goat's eye or in a simulator. ${ }^{20}$ The radialization of capsulorhexis can be prevented by performing it in a well-formed anterior chamber, since a shallower anterior chamber has a higher risk of radialization. ${ }^{21}$ In our study, radialization of the anterior lens capsule was attributed either due to a shallow anterior chamber or excessive egress of viscoelastic on the opening of the tunnel.

Hydro-dissection is the next most important step. ${ }^{22}$ Excessive fluid usage during hydrodissection may raise intraocular pressure inside the eye, with fluid pushing the superior iris through the tunnel and leading to its prolapse. ${ }^{23}$ Once the iris prolapse happens, it leads to floppiness of the tissue eventually causing excessive manipulation of the iris tissue. ${ }^{24}$ Hence, it is recommended by the authors to avoid excessive hydrodissection and avoid touching the iris throughout the procedure. If there is any prolapse, it is again recommended not to overfill the chamber with viscoelastic.

In cases of posterior capsular rupture for beginners, it is always recommended to accept the help of their mentors. ${ }^{25}$ Incomplete removal of the anterior vitreous leads to persistent macular edema. ${ }^{26}$ Inadvertent vitreous extending to the section may induce a tractional forces along the anterior part of the retina, eventually causing peripheral retinal tears and retinal detachment. ${ }^{27}$ Hence, it is necessary for all residents to have considerable training before managing a posterior capsular tear. ${ }^{28}$ Similarly, in our study, cases with posterior capsular compromise and vitreous disturbance were managed by a senior consultant who had extensive experience in cataract surgery.

The postoperative clinical evaluation of eyes is also an important part of the clinical curriculum of residents. ${ }^{29}$ Detailed evaluation of the anterior segment in POD1 helps residents to retrospectively analyse their precision of steps performed and to rectify it for future surgeries. It has a significant learning curve, especially for identifying cases that require further intervention. ${ }^{30}$ In our study, all of the cases in POD1 were evaluated by both residents and a senior consultant regarding postoperative visual outcome and satisfaction. Cases requiring further surgical intervention were performed by senior consultants, and the concerned resident was required to observe the management.

The present study is comparable to the Aravind study on resident learning curve in terms of percentage of postoperative complications and surgical re-intervention. ${ }^{6}$ This shows similar efficiency of all junior surgeons across the world requiring focused and effective training to eventually lead them to experts in patient care.

\section{Conclusion}

The learning curve of the residents varies from surgeon to surgeon; however, every resident needs to understand their own learning curve by scrutinizing their own operated cases. ${ }^{31}$ Once they are confident in performing cases with well-dilated pupils and a moderate grade of cataract, then they can start operating on complicated cases. ${ }^{32}$ In our study, we observed that residents often struggled in creating a perfect tunnel; nevertheless, with experience they were more comfortable. A well-formed tunnel reduces surgical time and the risk of intraoperative complications. ${ }^{33}$ Iris manipulation is the second most common complication that occurred recurrently with residents, and which can be reduced with good tunnel construction and averting iris touch throughout the procedure. The limitations of this study include its small sample size. We need similar studies from multiple centres to create a larger database eventually creating a unified training program for future residents and focusing them on the specific aspects of cataract surgery in wet-labs and simulators before performing their first surgery in similar lines of OLIMPICS (The Ophthalmic Learning and Improvement Initiative in Cataract Surgery) study where the respondents having preliminary training in wet lab developed faster proficiency in cataract surgery compared to respondents without wet lab training. ${ }^{34,35}$

\section{Acknowledgments}

This paper was presented at the ESCRS Paris conference as a presentation talk with interim findings on Monday 16 September 2019, Session Time: 12:15-12:51. The paper's abstract was published in ESCRS abstract archives (https://www.escrs.org/abstracts/details.asp? confid= $\underline{28 \& \text { sessid }=1321 \& \text { type }=\text { free } \& \text { paperid }=34480 \text { ). }}$.

\section{Disclosure}

The authors reported no conflicts of interest for this work. 


\section{References}

1. Grover AK. Residency training in India: time for a course correction. Indian J Ophthalmol. 2018;66(6):743-744. doi:10.4103/ijo.IJO_328_18

2. Honavar SG. Ophthalmology residency training in India: Quo vadis? Indian $J$ Ophthalmol. 2017;65(6):427-428. doi:10.4103/ijo. IJO_502_17

3. Gogate P, Biswas P, Natarajan S, et al. Residency evaluation and adherence design study: young ophthalmologists' perception of their residency programs - Clinical and surgical skills. Indian J Ophthalmol. 2017;65(6):452-460. doi:10.4103/ijo.IJO_643_16

4. Liu YC, Wilkins M, Kim T, Malyugin B, Mehta JS. Cataracts. Lancet. 2017;390(10094):600-612. doi:10.1016/S0140-6736(17) 30544-5

5. Chen X, Zafar S, Sikder S, et al. National survey and outcomes of resident-performed cataract surgery in monocular patients in the United States. J Cataract Refract Surg. 2019;45(7):939-945. [PMID: 31126781]. doi:10.1016/j.jcrs.2019.02.018

6. Bernhisel A, Pettey J. Manual small incision cataract surgery. Curr Opin Ophthalmol. 2020;31(1):74-79. doi:10.1097/ICU.0000000000000624

7. Gupta S, Haripriya A, Vardhan SA, Ravilla T, Ravindran RD. Residents' learning curve for manual small-incision cataract surgery at Aravind Eye Hospital, India. Ophthalmology. 2018;125 (11):1692-1699. doi:10.1016/j.ophtha.2018.04.033

8. Clarke C, Ali SF, Murri M, et al. Outcomes and complication rates of primary resident-performed cataract surgeries at a large tertiary-care county hospital. J Cataract Refract Surg. 2017;43(12):1563-1570. doi:10.1016/j.jcrs.2017.09.025

9. Ramani S, Pradeep TG, Sundaresh DD. Effect of wet-laboratory training on resident performed manual small-incision cataract surgery. Indian J Ophthalmol. 2018;66(6):793-797. doi:10.4103/ijo. IJO_1041_17

10. Singh K, Misbah A, Saluja P, Singh AK. Review of manual small-incision cataract surgery. Indian J Ophthalmol. 2017;65 (12):1281-1288. doi:10.4103/ijo.IJO_863_17

11. Muralikrishnan R, Venkatesh R, Prajna NV, Frick KD. Economic cost of cataract surgery procedures in an established eye care centre in Southern India. Ophthalmic Epidemiol. 2004;11(5):369-380. doi:10.1080/09286580490888762

12. Ruit S, Gurung R, Vyas S. The role of small incision suture-less cataract surgery in the developed world. Curr Opin Ophthalmol. 2018;29(1):105-109. doi:10.1097/ICU.0000000000000442

13. Haripriya A, Chang DF, Reena M, Shekhar M. Complication rates of phacoemulsification and manual small-incision cataract surgery at Aravind Eye Hospital. J Cataract Refract Surg. 2012;38 (8):1360-1369. doi:10.1016/j.jcrs.2012.04.025

14. Martens R, Nathoo N, Sidhu R, Gingerich A. Mapping the landscape of cataract surgery teaching assessment in Canadian residency programs. Can J Ophthalmol. 2019;54(2):155-158. doi:10.1016/j. jcjo.2018.04.023

15. Gogate PM. Small incision cataract surgery: complications and mini-review. Indian J Ophthalmol. 2009;57(1):45-49. doi:10.4103/ 0301-4738.44512

16. Pham DT, Wollensak J, Liekfeld A. Selbstschliessender korneoskleraler Tunnelschnitt in der Kataraktchirurgie [Self-closing corneoscleral tunnel incision in cataract surgery]. Ophthalmologe. 1996;93 (1):8-11.

17. Archana S, Khurana AK, Chawla U. A comparative study of sclero-corneal and clear corneal tunnel incision in manual small-incision cataract surgery. Nepal $J$ Ophthalmol. 2011;3 (1):19-22. doi:10.3126/nepjoph.v3i1.4273

18. Parkar T, Gogate P, Deshpande M, Adenwala A, Maske A, Verappa K. Comparison of subtenon anaesthesia with peribulbar anaesthesia for manual small incision cataract surgery. Indian J Ophthalmol. 2005;53(4):255-259. doi:10.4103/0301-4738.18907
19. Gimbel HV, Neuhann T. Development, advantages, and methods of the continuous circular capsulorhexis technique. J Cataract Refract Surg. 1990;16(1):31-37. doi:10.1016/s0886-3350(13)80870-x

20. Agapitos PJ. Cataract surgical techniques. Curr Opin Ophthalmol. 1991;2(1):16-27. doi:10.1097/00055735-199102000-00003

21. Colné J, Conart JB, Luc A, Perrenot C, Berrod JP, Angioi-Duprez K. Simulateur de chirurgie de cataracte EyeSi: validité de construction des modules capsulorhexis, phacoémulsification et aspiration des masses cristalliniennes [EyeSi surgical simulator: construct validity of capsulorhexis. J Fr Ophtalmol. 2019;42(1):49-56. French. doi:10.1016/j.jfo.2018.02.029

22. Marques FF, Marques DM, Osher RH, Osher JM. Fate of anterior capsule tears during cataract surgery. $J$ Cataract Refract Surg. 2006;32(10):1638-1642. doi:10.1016/j.jcrs.2006.05.013

23. Zawar SV, Gogate P. Safety and efficacy of temporal manual small incision cataract surgery in India. Eur $J$ Ophthalmol. 2011;21 (6):748-753. doi:10.5301/EJO.2011.6521

24. Blumenthal M, Ashkenazi I, Assia E, Cahane M. Small-incision manual extracapsular cataract extraction using selective hydrodissection. Ophthalmic Surg. 1992;23(10):699-701.

25. Kaushik NC, Morgan LH, Morrison AM. Iris prolapse following cataract surgery. Trans Ophthalmol Soc U K. 1983;103(Pt 5):560-561.

26. Chakrabarti A, Nazm N. Posterior capsular rent: prevention and management. Indian $J$ Ophthalmol. 2017;65(12):1359-1369. doi:10.4103/ijo.IJO_1057_17

27. Narendran N, Jaycock P, Johnston RL, et al. The cataract national dataset electronic multicentre audit of 55,567 operations: risk stratification for posterior capsule rupture and vitreous loss. Eye (Lond). 2009;23:31-37. doi:10.1038/sj.eye.6703049

28. Lundström M, Behndig A, Kugelberg M, et al. Decreasing rate of capsule complications in cataract surgery: eight-year study of incidence, risk factors, and data validity by the Swedish national cataract register. J Cataract Refract Surg. 2011;37:1762-1767. doi:10.1016/j. jcrs.2011.05.022

29. Najjar DM, Awwad ST. Cataract surgery risk score for residents and beginning surgeons. $J$ Cataract Refract Surg. 2003;29 (10):2036-2037. doi:10.1016/j.jcrs.2003.08.004

30. Benzekri R, Marie-Louise J, Chahed S. Évaluation du coût de l'enseignement de la chirurgie de la cataracte dans un établissement public de santé [Cost of teaching cataract surgery in a public hospital]. $J$ Fr Ophtalmol. 2017;40(10):860-864. doi:10.1016/j. jfo.2017.06.004

31. Westborg I, Mönestam E. Optimizing number of postoperative visits after cataract surgery: safety perspective. J Cataract Refract Surg. 2017;43(9):1184-1189. doi:10.1016/j.jcrs.2017.06.042

32. Borracci RA, Alvarez-Gallesio JM, Ciambrone G, Mezzadri NA. Self-estimation of surgical skills and competencies based on the learning curve theory in medical residents and fellows. Autoestimación de habilidades y competencias quirúrgicas basadas en la teoría de la curva de aprendizaje en médicos residentes y becarios. Cir Cir. 2019;87(4):416-422. doi:10.24875/ CIRU.18000664

33. Yen AJ, Ramanathan S. Advanced cataract learning experience in United States ophthalmology residency programs. J Cataract Refract Surg. 2017;43(10):1350-1355. doi:10.1016/j.jcrs.2017.10.014

34. Lynds R, Hansen B, Blomquist PH, Mootha VV. Supervised resident manual small-incision cataract surgery outcomes at large urban United States residency training program. J Cataract Refract Surg. 2018;44(1):34-38. doi:10.1016/j.jcrs.2017.09.032

35. Dean WH, Gichuhi S, Buchan JC, et al. Intense simulation-based surgical education for manual small-incision cataract surgery: the ophthalmic learning and improvement initiative in cataract surgery Randomized Clinical Trial in Kenya, Tanzania, Uganda, and Zimbabwe. JAMA Ophthalmol. 2021;139(1):9-15. doi:10.1001/ jamaophthalmol.2020.4718 


\section{Publish your work in this journal}

Clinical Ophthalmology is an international, peer-reviewed journal covering all subspecialties within ophthalmology. Key topics include: Optometry; Visual science; Pharmacology and drug therapy in eye diseases; Basic Sciences; Primary and Secondary eye care; Patient Safety and Quality of Care Improvements. This journal is indexed on PubMed

Submit your manuscript here: https://www.dovepress.com/clinical-ophthalmology-journal
Central and CAS, and is the official journal of The Society of Clinical Ophthalmology (SCO). The manuscript management system is completely online and includes a very quick and fair peer-review system, which is all easy to use. Visit http://www.dovepress.com/ testimonials.php to read real quotes from published authors. 